\title{
Are You Seeing This? What Is Available and How Can We Include Blind Students in Virtual UML Learning Activities
}

\author{
Leandro Luque ${ }^{12}$, Leônidas O. Brandão ${ }^{3}$, Romero Tori' ${ }^{1}$, Anarosa A. F. Brandão ${ }^{1}$ \\ ${ }^{1}$ Escola Politécnica - University of Sao Paulo (USP) \\ CEP 05.508-010 - Sao Paulo, SP - Brazil \\ ${ }^{2}$ Sao Paulo State Technological College - Fatec Mogi das Cruzes (Fatec-MC) \\ CEP 08.773-600 - Mogi das Cruzes, SP - Brazil \\ ${ }^{3}$ Institute of Mathematics and Statistics - University of Sao Paulo (USP) \\ CEP 05.508-090 - Sao Paulo, SP - Brazil \\ \{leandro.luque, anarosa.brandao, tori\}@usp.br, leodime.usp.br
}

\begin{abstract}
The inclusion of blind students in computer education programs involves several challenges. When considering virtual learning activities of UML - Unified Modeling Language, lecturers cannot use some of the solutions adopted in the traditional classroom. In this context, this paper presents the main challenges related to the inclusion of blind students in virtual learning activities of UML, establishes the requirements needed to make this inclusion possible and discusses whether existing tools can be used for this purpose. The results indicate a lack of solutions that enable the inclusion of blind students in these activities without affecting transactional distance.
\end{abstract}

\section{Introduction}

There has been a growing interest worldwide in promoting inclusion, which can be seen, for example, by the establishment of laws and public policies that seek to ensure the rights of different social groups [Mazzotta and D'Antino 2011]. Nevertheless, many people remain excluded from education systems, employment, among others [Marlier et al. 2007].

In some cases, only cultural changes may promote inclusion, such as those related to religion or race [Pless and Maak 2004]. However, in other cases (e.g. people with special needs and elderly people), it may be necessary the development of solutions, known as assistive technologies, that increase, maintain, or improve capabilities [Cook and Polgar 2013].

Although the computing field plays an important role as a mean for developing and delivering software solutions for a wide range of domains, many tools and technologies used in the field are not accessible, hindering the inclusion in computer education programs and in the industry [Luque et al. 2014].

Among these inaccessible tools and technologies we could cite graphical notations [Metatla et al. 2008] that, due to their nature, impose barriers to blind people the most common type of disability in Brazil [Ramires et al. 2013] and in the world [UN 
2013]. UML - Unified Modeling Language is the most used graphical notation in the development of software systems [Dobing and Parsons 2006], widely adopted in the industry and part of the reference curricula for the field [Luque et al. 2014].

In computer education programs, many lecturers use UML diagrams to teach students object oriented concepts [Owen et al. 2014], and blind students are usually not allowed to prove their knowledge with alternative tasks [Müller 2012].

Therefore, in order to convey graphical information to blind students in classroom activities, lecturers may use embossing pens and printers [Lötzsch 1994] (Figure 1a), Braille displays [Cowens et al. 1996] (Figure 1b), objects with specific semantics [Brookshire 2006; McMullen and FitzPatrick 2009; Owen et al. 2014] (Figure 1c), among others.

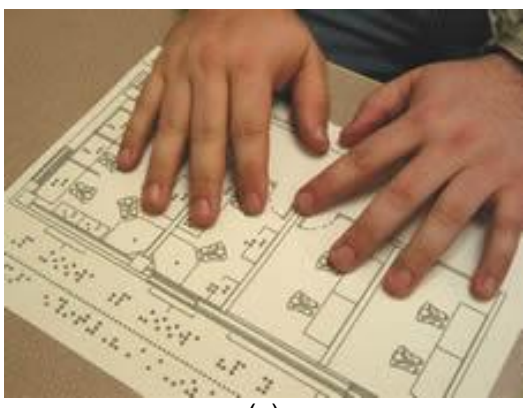

(a)



(b)

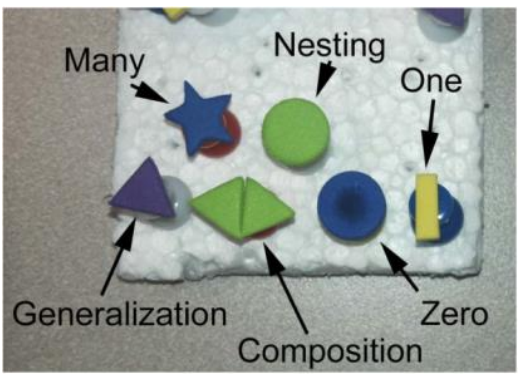

(c)

Figure 1. (a) Tactile diagram (b) Braille display (c) Objects used to represent UML elements

Some of these tools, such as embossing pens and objects, allow lecturers to carry out interactive activities with blind and sighted students (e.g. the collaborative creation of a diagram or the identification of errors in a previously created diagram).

However, when considering virtual learning activities, which have been growing and are likely to continue growing in blended and distance education programs [Alonso 2010; Arrigo 2005], the use of these tools becomes difficult. This difficulty arises mainly from the lack of physical interaction with the lecturer, considering the spatial distance between him/her and the students, as well as the limited availability and high cost of haptic devices. In this paper, the term "virtual learning activities" refers to those mediated by computers and carried out with the existence of spatial and possibly temporal distance between the participants and content.

One approach that can be followed to reduce this difficulty is to predefine the activity graphical content and keep it constant, allowing lecturers to delivery materials (e.g. tactile diagrams) to students in advance.

However, this may lead to an increase in the rigidity of the education program and negatively influence the teaching and learning process. This rigidity may influence the transactional distance and may help creating an increasing sense of closeness or distance between the participants.

The transactional distance can be defined as the psychological and communications space to be crossed in interactions between lecturers and students [Azevedo 2002], and it is increased by the occurrence of spatial and/or temporal 
distance. The lower the flexibility of the education program, the less opportunity for dialogue and interference during the development of the course [Moore 2002; Tori 2010]. Hence, the fixation of the graphical content can reduce the autonomy of students and result in demotivation. For instance, diagrams based on situations raised during class, which could increase student motivation, can no longer be used in an inclusive scenario.

In this context, this paper aims to establish the requirements and to identify existing solutions that allow the inclusion of blind students in virtual learning activities of UML, with the lowest impact on transactional distance. Besides establishing the requirements and validating existing solutions on the fulfillment of these requirements, this paper emphasizes the importance of further research in this area.

The remainder of the paper is organized as follows. Section 2 presents a background on virtual learning and accessibility. Section 3 describes the method followed in this research. Section 4 reviews the relevant literature and the tools related to the accessibility of UML diagrams. Section 5 establishes and discusses the requirements to include blind students in virtual learning activities of UML. In section 6 , the tools and solutions proposed in the literature are validated on the fulfillment of these requirements. Finally, in Section 7, the conclusions are presented.

\section{Background}

Blind people receive information from the environment through other senses, mainly hearing and touch. When interacting with computers, the information is generally transmitted using sounds, Braille printers and displays. Data input is usually done using keyboards - menus and shortcuts - and voice commands [Christian 2000]. Although touch is the most commonly used sense by blind people for accessing graphical information in classroom, sound interfaces are more common when interacting with computers [Massof 2003]. A common solution for this type of interface is the use of screen readers, which synthesize textual information present in graphical interfaces.

Blind people face several challenges when using graphical user interfaces, mainly due to the way information is presented and accessed - screen readers cannot read pixels, and blind people do not effectively use the mouse [Brookshire 2006].

Virtual Learning Environments - VLE are used in distance and blended learning to support the interaction between lecturers, students and content [Penterich 2005]. They offer a variety of features, including: access control, course management, content management, virtual drive, instant messaging, whiteboard, among others [Tori 2010]. An important aspect of VLE is the degree of accessibility they offer to users. Accessibility can be defined as the ease of accessing and using products and services. When considering computing products, it is known as digital accessibility [Luque and Silva 2011].

The accessibility of VLE involves both technological and methodological aspects [Arrigo, 2005]. If only one of these aspects is present, the accessibility may be unsatisfactory. An environment developed in compliance with accessibility standards will not be accessible to blind users if the content it delivers has been designed for sighted users, with graphs and charts without textual descriptions. Although many VLE 
are technologically accessible [Piovesan et al. 2013], there is still a major concern with the accessibility of the content available in these environments. According to a survey conducted by Tabs et al. (2003), 33\% of institutions that offered online courses in 2000 and 2001 in the USA reported not knowing if their systems were in compliance with accessibility standards, 3\% did not follow standards and $18 \%$ followed only some standard aspects. We have not found similar data for Brazilian institutions.

\section{Method}

To establish the requirements for integrating blind students into virtual learning activities of UML, we initially performed a literature review to identify studies related to the accessibility of UML diagrams. After that, we combined information gathered from the review with experience of one of the authors on teaching UML for a blind student in an Object-Oriented Analysis course to establish the proposed requirements.

The literature review involved the identification of references and citations related to the main studies published about the subject, identified in a previous research [Luque et al. 2014]. For the ones that proposed tools, we also searched for the tools on Google, trying to verify its availability to end users.

During this search phase, we identified other tools, not cited in the reviewed studies, that allow the creation and editing of UML diagrams through text. To gather more information about these tools, we conducted new Google searches on 05/03/2014, using the search string ("UML from text" OR "textual UML" OR "UML textual" OR "UML em texto"). All websites listed as relevant by Google were visited and those related to the tools were recorded. Thus, we visited the official websites of these tools and collected more information about them.

Finally, we analyzed the fulfillment of the requirements by each solution and tool found in the review.

\section{Literature Review}

Despite the large number of published studies investigating the accessibility of different types of diagrams and graphs, there are a few studies about the accessibility of UML diagrams for blind people.

King et al. (2004) proposed a software system that would be able to extract relevant technical content from diagram images and allow blind users to explore it. Although the project failed to achieve its goals, it generated a sub product, known as Accessible UML, that reads XMI (XML Metadata Interchange) files of use case and class diagrams, which are commonly exported by Computer-Aided Software Engineering - CASE tools, and presents its information in a tree hierarchy that can be navigated through the keyboard and accessed via audio. It does not allow diagram editing. The software is available at www.alasdairking.me.uk/tedub/index.htm.

Brookshire (2006) reported his experience with the use of tactile cards to teach diagrams to blind students. His experience indicates that it can be used in interactive activities without spatial distance. Müller (2012) discussed his experience in teaching UML to two blind students using tactile diagrams (Emprint- ViewPlus), together with 
textual description, through a table structure (class) and a message list (sequence). No experiment was conducted to compare his approach with existing ones.

Silva et al. (2010) and Pansanato et al. (2012) proposed the use of a tabular structure, similar to those of spreadsheets, to enable blind students to access and create diagrams. Santos et al. (2012) propose a tool that enables the accessing and editing of diagrams by blind people using different types of keyboard interaction.

In Grillo et al. (2012), it is proposed a technique for collaborative work between blind and sighted people, in which two views for the same model are generated: a textual and a graphical. When the model is changed, the different views are synchronized. The tool, known as AWMo, is available at garapa.intermidia.icmc.usp.br:3000/awmo/textual.jsf. Metatla et al. (2012) also focus on collaborative work. It presented a strategy to support collaborative work between sighted and blind users through multimodal interfaces. The tool set, known as CCml, is available for download at: http://ccmi.eecs.qmul.ac.uk.

Loitsch and Weber (2012) proposed a haptic and audio-based explorer, called HyperReader, which allows blind people to access the information present in UML sequence diagrams. It can be integrated with Visio to enable the collaboration with sighted people.

In addition to studies on UML diagrams' accessibility, some general approaches seek to make any type of diagram available [Luque et al. 2014]. Unfortunately, with only three exceptions [King et al. 2004, Grillo et al. 2012, Metatla et al. 2012], tools were not available for download and use.

With regard to the tools searched on Google not cited in the reviewed studies, we visited 100 sites considered relevant by Google. 26 of them had references to tools (Table 1). A total of 20 different web-base and desktop tools were found.

Each tool specifies a DSL - Domain Specific Language that can be used for specifying diagrams. All of them allow the user to create visual representations of diagrams from a textual specification.

Table 1. Tools, their availability and supported diagrams

\begin{tabular}{lll} 
Tool & Availability & Supported Diagrams \\
AWMo & Web & Class \\
\hline Diagrammr & Web & Communication and Sequence \\
\hline EasyUML Editor & Discontinued \\
\hline Finite State M. D. Gen. & Not Found \\
\hline js-sequence-diagrams & Web & Sequence \\
\hline LightUML & Desktop & Class \\
\hline MetaUML & Web & Activity, Use Case, Class, State and Package \\
\hline Modsl & Desktop & Class and Collaboration \\
\hline & & Activity, Use Case, Class, Component, State, \\
PlantTextUML Editor & Web & Object and Sequence \\
\hline & & Activity, Use Case, Class, Component, State, \\
PlantUML & Web & Object and Sequence \\
\hline Quick Sequence D. Editor & Desktop & Sequence \\
\hline
\end{tabular}




\begin{tabular}{lll}
\hline SeedUML & Web & Sequence \\
\hline Seqdiag & Web and & \\
TextUML Toolkit & Desktop & Sequence \\
\hline UML Graph & Desktop & Class \\
\hline UMLet & Desktop & Class and Sequence \\
\hline & Desktop & Activity and Sequence \\
Umple & Web and & \\
USE & Desktop & Class and State \\
\hline WebSequenceDiagrams & Desktop & Class \\
\hline yUML & Web & Sequence \\
\hline
\end{tabular}

\section{The proposed requirements}

The studies found in the literature review focus on technological issues involved in the accessibility of UML diagrams. None of them addresses learning activities with spatial distance nor interactivity, an important component while considering transactional distance. Therefore, to define the requirements for including blind people in this type of activity, it is necessary to analyze the forms of interaction that can be established between lecturers, students and content during the process of teaching and learning.

Our analysis was based on the experience in teaching object-oriented analysis with UML, which led us to take five activities as common during the process: (i) presentation of diagrams and explanation of its structure/content; (ii) construction of diagrams step-by-step, individually or in collaboration with students; (iii) presentation of diagrams and questioning about problems in its structure/content; (iv) evaluation of diagrams created by third parties; and (v) peer reviews;

To enable the inclusion of blind students in these activities, they should be able to: access, create and edit diagrams in an accessible format; make them available to the lecturer and classmates; and access in real-time information about the elements that the lecturer is highlighting during presentations.

Therefore, we consider that to perform the aforementioned activities, the list of functional requirements presented in Table 2 must be fulfilled. They are specified as user stories.

Table 2. Functional requirements and its relation to aforementioned activities

\begin{tabular}{|c|c|c|c|c|c|}
\hline & Activities & 1 & ii iii & & $\mathrm{v}$ \\
\hline$\stackrel{\stackrel{\rho}{g}}{=}$ & $\begin{array}{l}\text { 1: graphically create and edit diagrams so that I can prepare presentations } \\
\text { and delivery content to students }\end{array}$ & & $\mathrm{X} \mid \mathrm{X}$ & & \\
\hline$\frac{3}{3}$ & $\begin{array}{l}\text { 2: highlight aspects of diagrams I am presenting, creating or editing, so that } \\
\text { students can follow the explanation and collaborate }\end{array}$ & $x$ & $\mathrm{X} \mid \mathrm{X}$ & & \\
\hline $\begin{array}{l}\bar{E} \\
\frac{\tilde{e}}{\sigma} \\
\end{array}$ & $\begin{array}{l}\text { 3: have graphical access to diagrams created by sighted students so that I } \\
\text { can correct their assignments }\end{array}$ & & & $\mathrm{X}$ & \\
\hline$\sum^{2}$ & $\begin{array}{l}\text { 4: have graphical access to diagrams created by blind students so that I can } \\
\text { correct their assignments }\end{array}$ & & & & \\
\hline
\end{tabular}




\begin{tabular}{|c|c|c|c|c|}
\hline \multirow{5}{*}{  } & $\begin{array}{l}\text { 5: follow changes in diagram creation activities carried out by lecturers in } \\
\text { order to collaborate }\end{array}$ & $\mathrm{X}$ & $\mathbf{K}$ & \\
\hline & $\begin{array}{l}\text { 6: follow the highlights made by lecturers during interactive activities, to } \\
\text { understand his/her explanation and collaborate, and to navigate through the } \\
\text { highlighted elements, identifying the information necessary for a proper } \\
\text { understanding }\end{array}$ & $X \mid X$ & $\mathrm{X} \mid \mathrm{X}$ & \\
\hline & $\begin{array}{l}\text { 7: access diagrams created by lecturers and by sighted classmates so that I } \\
\text { can do my assignments, exams and peer reviews }\end{array}$ & & $\mathrm{X}|\mathrm{X}| \mathrm{X}$ & $\mathrm{X} \mid \mathrm{X}$ \\
\hline & 8: access diagrams created by blind students so that I can peer review them & & & $\lambda$ \\
\hline & $\begin{array}{l}\text { 9: create diagrams and send them to lecturers and classmates so that I can } \\
\text { do assignments and exams }\end{array}$ & & & \\
\hline \multirow{5}{*}{ 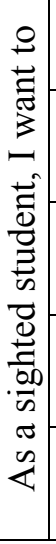 } & $\begin{array}{l}\text { 10: graphically follow diagram editing activities carried out by lecturers in } \\
\text { order to collaborate }\end{array}$ & $\mathrm{X}$ & $\mathrm{K}$ & \\
\hline & $\begin{array}{l}\text { 11: graphically follow the highlights made by lecturers during activities, to } \\
\text { be able to follow his/her explanation and collaborate }\end{array}$ & $X \mid X$ & $x \mid$ & \\
\hline & $\begin{array}{l}\text { 12: graphically access diagrams created by lecturers and sighted classmates, } \\
\text { to be able to perform tasks, assessments and peer reviews }\end{array}$ & $\mathrm{X}$ & $x|x|$ & \\
\hline & $\begin{array}{l}\text { 13: graphically access diagrams created by blind students, to be able to } \\
\text { perform peer reviews }\end{array}$ & & & \\
\hline & $\begin{array}{l}\text { 14: graphically create diagrams and make them available to lecturers and } \\
\text { classmates in response to assignments }\end{array}$ & & & \\
\hline
\end{tabular}

We did not consider requirements related to the way students and lecturers comment on diagrams created by others in evaluation and review activities, as this is generally done in an accessible way.

Despite we considered only blind people until now, these requirements are valid for including people with any degree of visual impairment.

\section{Requirements fulfillment: what is currently available?}

None of the solutions/tools found in the review fulfill all requirements when considering the existence of spatial distance. In Table 3, we present the relation between the reviewed studies and the established requirements. We did not list the requirements 1,3 , $10,11,12$ and 14 because they can be fulfilled through existing technologies, such as video lectures and CASE tools.

Table 3. Relation between reviewed studies and requirements

\begin{tabular}{|c|c|c|c|c|c|c|c|c|}
\hline & \multicolumn{8}{|c|}{ Requirement } \\
\hline Study & 2 & 4 & 5 & 6 & 7 & 8 & 9 & 13 \\
\hline [King et al. 2004] & & & Partially & & $\mathrm{OK}$ & $\mathrm{OK}$ & & \\
\hline [Brookshire 2006] & OK & OK & $\mathrm{OK}$ & $\mathrm{OK}$ & OK & $\mathrm{OK}$ & OK & $\mathrm{OK}$ \\
\hline $\begin{array}{l}\text { [Silva et al. 2010] } \\
\text { [Pansanato et al. 2012] }\end{array}$ & & & & & & OK & & \\
\hline
\end{tabular}




\begin{tabular}{|c|c|c|c|c|c|c|c|c|}
\hline [Grillo et al. 2012] & & $\mathrm{OK}$ & Partially & & $\mathrm{OK}$ & $\mathrm{OK}$ & $\mathrm{OK}$ & $\mathrm{OK}$ \\
\hline [Loitsch and Weber 2012] & & $\mathrm{OK}$ & Partially & & $\mathrm{OK}$ & $\mathrm{OK}$ & $\mathrm{OK}$ & $\mathrm{OK}$ \\
\hline [Metatla et al. 2012] & & $\mathrm{OK}$ & Partially & & $\mathrm{OK}$ & $\mathrm{OK}$ & $\mathrm{OK}$ & $\mathrm{OK}$ \\
\hline [Müller 2012] & $\mathrm{OK}$ & & Partially & $\mathrm{OK}$ & & $\mathrm{OK}$ & & \\
\hline [Santos et al. 2012] & & $\mathrm{OK}$ & Partially & & OK & $\mathrm{OK}$ & $\mathrm{OK}$ & $\mathrm{OK}$ \\
\hline
\end{tabular}

Considering only the solutions that supports some degree of interactivity, those proposed by Brookshire (2006) and Müller (2012) limit the interaction when applied to virtual learning activities of UML as they use tactile cards and embossing printers, requiring the delivery of materials to students in advance and resulting in a greater level of rigidity of the education program. The solution proposed by Loitsch and Weber (2012) involves the use of a special tactile explorer and therefore incurs in high costs.

The most promising studies for the presented context - that fulfill the highest number of requirements - are [Grillo et al. 2012] and [Metatla et al. 2012], allowing diagram accessing, creation and editing through both textual and graphical interfaces. However, none of them meets the requirements 2 and 6, making it impossible to conduct an activity in which examples are chosen during class and all students can participate collaboratively.

With regard to textual UML tools, web based would be appropriate for integration with virtual learning environments. However, most of them only allows the generation of diagrams from text, fulfilling the requirements 9 and 4. Exceptions are the $\mathrm{AWMo}, \mathrm{CCml}$ and tools that meet the same requirements mentioned above.

In this context, it is evident the need for studies that seek to identify ways of meeting the functional requirements 2 and 6 , allowing more interactive virtual learning activities of UML, with few impact on transactional distance.

\section{Conclusions}

This paper presented the main challenges for the inclusion of blind students in interactive virtual activities of UML. We defined the requirements necessary to enable this inclusion and reviewed existing approaches, solutions and tools, validating them on the fulfillment of the established requirements.

The results indicated a lack of tools that meet all established requirements and therefore it is not fully possible to include blind people in UML virtual learning activities with low impact on the transactional distance. To change this scenario, it is necessary further research and technology development effort. A tool that implements all the established requirements is under development and future work will mainly cover tests with this tool in interactive virtual learning activities of UML.

\section{Acknowledgements}

This work is partially supported by grant 2014/Dr-02 (TOSHIBA-EPUSP) and grant \#2011/10926-2, São Paulo Research Foundation (FAPESP). 


\section{References}

Alonso, K. M. (2010). A expansão do ensino superior no Brasil ea EaD: dinâmicas e lugares. Educação \& Sociedade, 31(113), 1319-1335.

Arrigo, M. (2005). E-learning accessibility for blind students. Recent Research Developments in Learning Technologies.

Azevedo, W. (2002). Teoria da distância transacional. Revista Brasileira de Aprendizagem Aberta e a Distância.

Brookshire, R. G. (2006). Teaching UML Database Modeling to Visually Impaired Students. Issues in Information Systems, 7(1), 98-101.

Christian, K. (2000). Design of haptic and tactile interfaces for blind users. Department of Computer Science, University of Maryland.

Cook. A. M. and Polgar, J. M. (2013) Cook and Hussey's assistive technologies: principles and practice. Elsevier Health Sciences, 2013.

Cowens, M. W., Gilkes, A. M., \& Taylor, L. A. (1996). U.S. Patent No. 5,580, 251. Washington, DC: U.S. Patent and Trademark Office.

Dobing, B. and Parsons, J. (2006). How UML is used. Communications of the ACM, 49(5), 109-113.

Grillo, F. D. N., de Mattos Fortes, R. P. and Lucrédio, D. (2012). Towards collaboration between sighted and visually impaired developers in the context of Model-Driven Engineering. Available at < http://www.dsmforum.org/events/gmld12/papers/Grillo.pdf $>$. Visited: 8th may 2014.

King, A., Blenkhorn, P., Crombie, D., Dijkstra, S., Evans, G. and Wood, J. (2004). Presenting UML software engineering diagrams to blind people. In Computers Helping People with Special Needs (pp. 522-529). Springer Berlin Heidelberg.

Loitsch, C. and Weber, G. (2012). Viable haptic UML for blind people. In Computers Helping People with Special Needs (pp. 509-516). Springer Berlin Heidelberg.

Lötzsch, J. (1994). Computer-aided access to tactile graphics for the blind. In Computers for Handicapped Persons (pp. 575-581). Springer Berlin Heidelberg.

Luque, L. and Silva, R. R. (2011). Acessibilidade em Java. JavaMagazine, 96, Rio de Janeiro.

Luque, L., Veriscimo, E. S., Pereira, G. C., \& Filgueiras, L. V. L. (2014). Can We Work Together? On the Inclusion of Blind People in UML Model-Based Tasks. In Inclusive Designing (pp. 223-233). Springer International Publishing.

Marlier, E. (Ed.). (2007). The EU and social inclusion: facing the challenges. The Policy Press.

Massof, R. W. (2003). Auditory assistive devices for the blind. In International Conference on Auditory Display, Boston (pp. 271-275).

Mazzotta, M. J. S. and D'Antino, M. E. F. (2011). Inclusão social de pessoas com deficiências e necessidades especiais: cultura, educação e lazer. Saúde e Sociedade, 20(2), 377-389. 
McMullen, D. and Fitzpatrick, D. (2009). Autonomous access to graphics for visually impaired learners. Available at: $<$ http://ilta.ie/files/DeclanMcMullenEdTech2009.pdf>. Visited: 8th may 2014.

Metatla, O., Bryan-Kinns, N. and Stockman, T. (2008). Constructing relational diagrams in audio: the multiple perspective hierarchical approach. In Proceedings of the 10th international ACM SIGACCESS conference on Computers and accessibility.

Metatla, O. et al. (2012). Cross-modal collaborative interaction between visually impaired and sighted users in the workplace. Available at: < https://smartech.gatech.edu/jspui/bitstream/1853/44430/18/Metatla_ICAD2012.pdf $>$. Visited: 10th may 2014.

Moore, M. G. (2002) Teoria da distância transacional. Revista Brasileira de Educação a Distância, 1(1).

Müller, K. (2012). How to make unified modeling language diagrams accessible for blind students. In Computers Helping People with Special Needs (pp. 186-190).

UN (2013). Human functioning and disability. Disponível em: $<$ http://unstats.un.org/unsd/demographic/sconcerns/disability/disab2.asp >

Owen, C. B. et al. (2014). Teaching Modern Object-Oriented Programming to the Blind: An Instructor and Student Experience. ASEE Annual Conference.

Pansanato, L. T. E. et al. (2012). Projeto D4ALL: acesso e manipulação de diagramas por pessoas com deficiência visual. In Proceedings of the 11th Brazilian Symposium on Human Factors in Computing Systems (pp. 33-36).

Penterich, E. (2005). Ambientes virtuais de aprendizagem. Sala de Aula e Tecnologias. São Paulo: Editora da Universidade Metodista de São Paulo.

Piovesan, S. D. et al. (2013). Sistema Imersivo para Pessoas com Deficiência. In Anais do Simpósio Brasileiro de Informática na Educação, 24(1), 2013.

Pless, N. and Maak, T. (2004). Building an inclusive diversity culture: Principles, processes and practice. Journal of Business Ethics, 54(2), 2004.

Ramires, L. O. et al. (2013). Como a Tecnologia Assistiva tem auxiliado o Processo de Ensino/Aprendizagem? Mapeamento Sistemático a partir dos Trabalhos Publicados no SBIE. In Anais do Simpósio Brasileiro de Informática na Educação, 24 (1).

Santos, L. G., Bandeira, A. L., Pansanato, L. T., \& Paiva, D. (2012). Recursos de acessibilidade para auxiliar a navegação de estudantes cegos em um editor de diagramas. In Anais do Simpósio Brasileiro de Informática na Educação, 23 (1).

Silva, C. E., Pansanato, L. T. and Fabri, J. A. (2010). Ensinando Diagramas UML para Estudantes Cegos. XVIII CIESC-XXXVI CLEI.

Tabs, E. D., Waits, T., \& Lewis, L. (2003). Distance education at degree-granting postsecondary institutions: 2000-2001. Washington: US Department of Education.

Tanaka, E. H., \& Rocha, H. V. D. (2004). O redesign do HagáQuê visando acessibilidade. In Anais do Simpósio Brasileiro de Informática na Educação, 1 (1).

Tori, R. (2010). Educação sem distância. Senac. 